able progress in the field of biovigilance, says Dr. Luc Noël, in charge of transplantation at the World Health Organization (WHO).

"In the last decade, the European Commission established directives requiring the vigilance and surveillance of cell and tissue transplantation and blood transfusions, and now there is a new directive for surveillance of organ transplantation practices that we hope will be put through in the coming months," he says. "These directives have resulted in projects like the Euro- pean Union Standards and Training for the Inspection of Tissue Establishments Project, which ran for three years and focused on inspection training and vigilance for tissue banks but also created tools that can now be used internationally for biovigilance and surveillance."

The project developed tools and assessment grids for member states of the European Union that can help identify how an adverse event should be reported and calculate the appropriate level of national and international reaction.

Those tools have since been stream- lined by the WHO for global application and were debuted at the Third Global Consultation on Regulatory Requirements for Human Tissues and Cells for Transplantation in Geneva, Switzerland in February.

WHO has also started development on a Global Knowledge Base on Transplantation, which lay people and regulatory authorities will be able to use to access information on biovigilance and surveillance. - Lauren Vogel, Ottawa, Ont.

DOI:10.1503/cmaj.109-3196

\title{
Where "stigma leaves the room"
}

Previously published at www.cmaj.ca

$\mathrm{W}$ hen Lt. Col. Stéphane Grenier returned to Canada in 1995 from a 10-month peacekeeping mission in Rwanda, he was as an injured man. He just didn't know it.

He had been part of the United Nations forces, under Lt. Gen. Roméo D'Allaire, who were caught in the middle of the militia-led massacre of 800000 Tutsis and moderate Hutus. For four years after his return, Grenier suffered from cold sweats, flashbacks, emotional outbursts and sleepless nights. He once sat in his car for 45 minutes outside a base clinic, trying to figure out how he was going to describe what was going on in his head.

Looking back, Grenier realizes he was oblivious to anything related to mental health problems. Now, as special adviser on operational stress injuries for the Canadian Forces, he is leading an effort to educate Canadian soldiers about mental health, so they will be better equipped to recognize and seek help for invisible wounds, like the post-traumatic stress disorder he came home with 15 years ago.

"We sometimes see mental health as less important than it should be, because we don't have the right language to describe it," Grenier says.

Simply being made more aware of mental health issues is not enough, says Grenier. A pamphlet won't cut it. So he created an educational campaign to reach military personnel of all ages, ranks and level of development. The

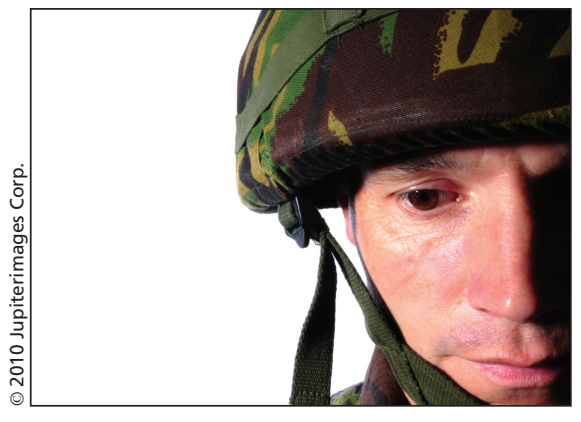

Soldiers are sometimes unaware that they return from combat with mental wounds, but the Canadian Forces is teaching them to recognize the signs.

goals are to educate them about mental injuries, to reduce stigma surrounding mental health problems and to change attitudes about seeking help.

One section is dedicated to broadening soldiers' understanding of what operational stress injuries are. For example, soldiers are taught that in addition to seeing a traumatic event, fatigue can lead to a mental health problem. The wear and tear of long days in the field adds up, says Grenier. "There's a cumulative effect on the body and the mind."

Other triggers include grief suffered because of the deaths of fellow soldiers and what Grenier refers to as "moral injuries," when the experiences of war affect core values, causing people to question beliefs they may have held their entire lives.

Another component of the education campaign is the teaching of a mental health continuum model that was developed in consultation with the United States Marines Corp. The old model of mental health, says Grenier, was too black and white - you were mentally sound or mentally ill. Soldiers learn that the mental health spectrum is more complex, and that all health, mental and physical, is dynamic and can worsen or improve depending on a person's circumstances. The continuum model consists of multiple stages: healthy, adaptive coping, mild and reversible distress, functional impairment, persistent impairment and clinical illness requiring concentrated care.

"We look at behaviours in the workplace and we give examples of problem behaviours at different stages, and we tell people what to do in each of these stages," says Grenier.

The mental health education is administered using an experiential approach rather than one based on traditional clinical theories. Soldiers tend to listen better to people who share their culture, Grenier says, so instructors include mental health professionals and members of the military who have suffered problems.

The instructors don't reveal their own stories right away, though, instead waiting until they have established credibility with the class. When they do disclose what they have been through, the effect on the students is apparent, says Grenier.

"Jaws drop," he says. "And stigma leaves the room." - Roger Collier, CMAJ

DOI:10.1503/cmaj.109-3197 